\title{
List of beetles (Coleoptera) associated with the oyster mushroom, Pleurotus ostreatus Fr., in the Onon-Balj National Park of Mongolia
}

\author{
Boo Hee Jung ${ }^{1}$ and Sun-Jae Park ${ }^{2, *}$ \\ ${ }^{1}$ Korean Entomological Institute, Korea University, Seoul 136-701, Korea \\ ${ }^{2}$ Animal Resources Division, National Institute of Biological Resources, Incheon 404-708, Korea \\ *Correspondent: sun1763@korea.kr
}

\begin{abstract}
We present a list of the beetle species associated with the oyster mushroom, Pleurotus ostreatus Fr. in the birch forest of Onon-Balj National Park in Mongolia. A total of 21 species in seven families were found in this fungus, including fungivorous species: Litargus japonicus Reitter and Mycetophagus antennatus (Reitter) (Mycetophagidae), Pseudamblyopus similis (Lewis) (Erotylidae), and Lordithon sp. (Staphylinidae) etc. Both adult and larval forms are presented in the checklist along with the type of fungal association, of which approximately 52 percent are obligate mycetobionts. The main trends of the ecological and trophic specialization of the mycetophilic beetles are discussed.
\end{abstract}

Keywords: fungal host, fungivorous beetles, Mongolia, Pleurotus ostreatus

\section{INTRODUCTION}

Basidiomycetes are the most commonly used foods of fungivorous Coleopteran beetles. Basidiomycetes which serves as hosts for beetles are composed mainly of two large groups; one of them is bracket fungi (order Aphyllophorales) which form spores within tubes and rarely on teeth, and the other is mushrooms (order Agaricales) which form spores on gill or rarely within tubes. Most Aphyllophorales are ligneous and most Agaricales are soft (Breitenbach and Kränzlin, 1986; Leschen, 1990; Kim et al., 2004). Insects feeding on bracket fungi appear to be more host-specific than insects feeding on mushrooms (Lawrence and Milner, 1996; Jung and Lee, 2011). The long lifespan and ecological succession of fruiting bodies of Aphyllophorales would contain more beetle species than softer, fleshy, more ephemeral Agaricales, although the latter often has a greater number of or abundance of beetles at any given time (Cline and Leschen, 2005).

Some fungivorus beetles including Erotylidae, Mycetophagidae, Tetratomidae and some Tenebrionidae are observed to be obligatory inhabitants of Basidiomycetes. In particular, woody and thick fungi of the order Aphyllophorales and Agaricales provide microhabitats in which many arthropod species spend their entire lives (Klimaszewski and Peck, 1987; Leschen, 1990; Jung and Kim, 2008; Jung and Lee, 2011). These fungi provide their inhabitants with food, shelter, and breeding places either directly or indirectly (Graves, 1960; Paviour-Smith, 1960; Klimaszewski and Peck, 1987; Wheeler, 1987; Cline and Leschen, 2005; Jung and Lee, 2011).

Among them, the oyster mushroom, Pleurotus ostreatus Fr. (Fig. 1) is distributed throughout temperate regions of the world (Lee, 1988; Kim et al., 2004; Cline and Leschen, 2005). These mushrooms are edible and in high demand by mushroom collectors and individual growers (Kim et al., 2004; Cline and Leschen, 2005).

Pleurotus ostreatus can be distinguished by the following combination of characters: caps laterally attached; cap 43-200 mm in length, fan-shaped to shallowly funnel-shaped; white to grayish or brownish color and rolled margin; slightly depressed in center; surface smooth and moist; fruiting bodies often conjoined and overlapping; stalk white, stout, smooth and short; gills descending stalk, close to nearly distinct and thick; spore print white (Lincoff, 1981; Lee, 1988; Kim et al., 2004; Cline and Leschen, 2005). This fungus is a decomposer of wood and is most often encountered on dying or dead deciduous trees (Lee, 1988; Kim et al., 2004), but rarely encountered on conifers (Vilgalys et al., 1993). It also typically begins to appear in late spring and persist throughout the summer and fall, and so is most abundant on cool and damp days in early to late autumn in deciduous forests (Cline and Leschen, 2005). 
Pleurotus ostreatus is an important fungal host for many mycophagous beetles in Europe and Asia (Donisthorpe, 1935; Scheerpeltz and Höfler, 1948; Benick,
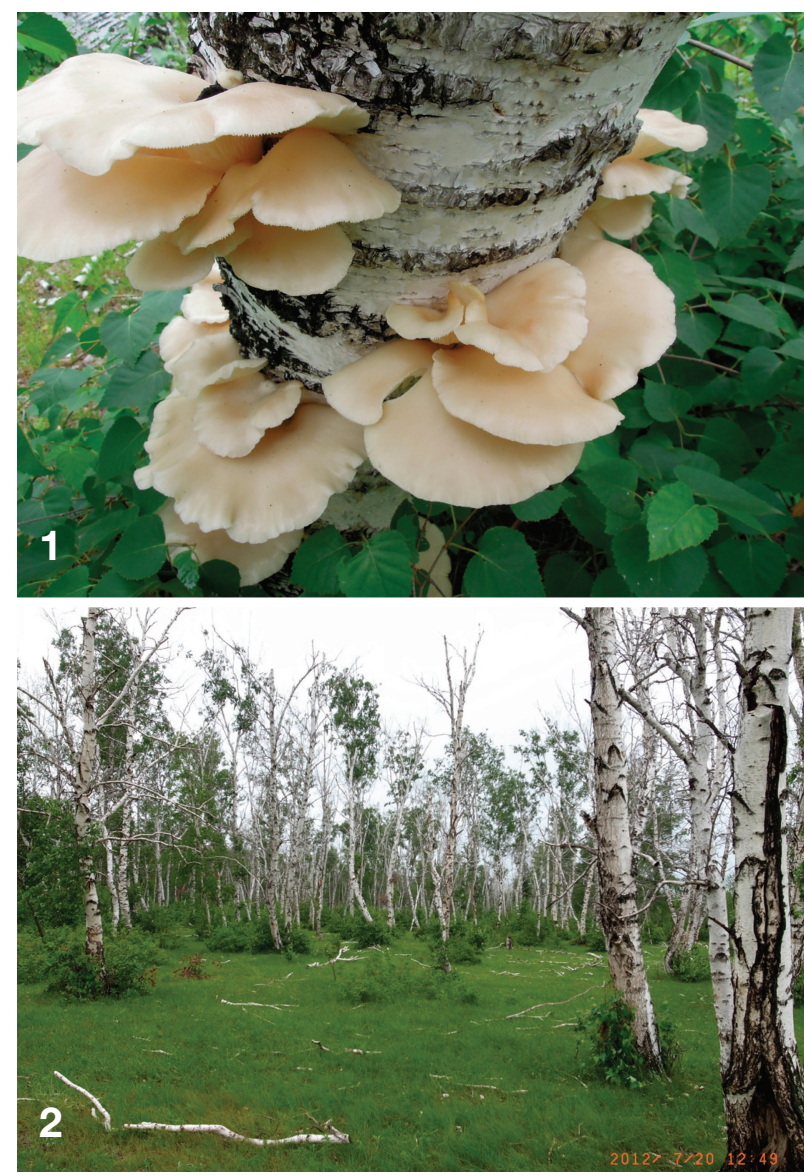

Figs 1-2. Pleurotus ostreatus in the Birch Forest of Onon-Balj National Park. 1. Pleurotus ostreatus. 2. Birch Forest.

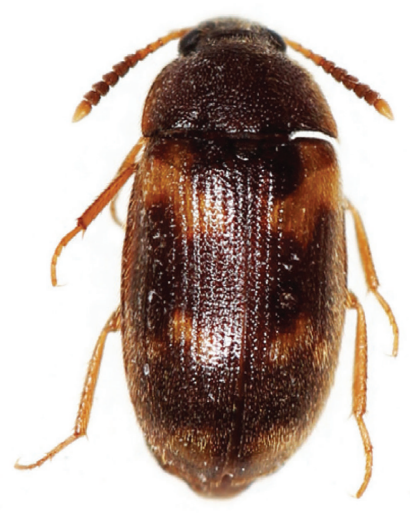

3

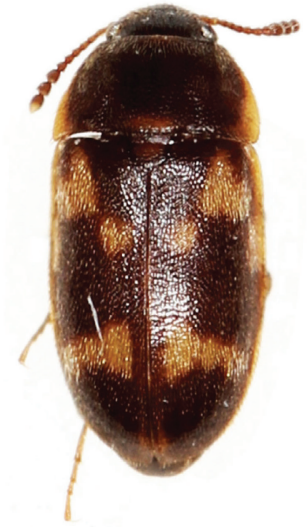

4

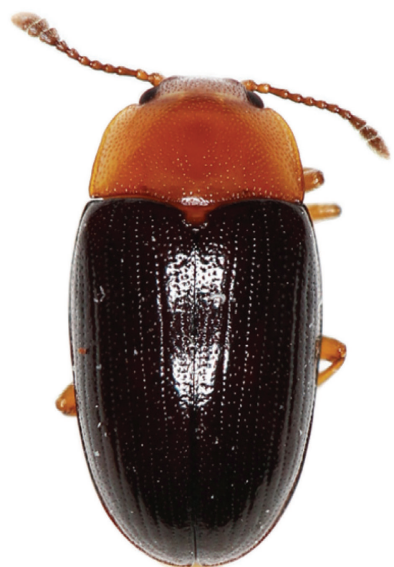

5

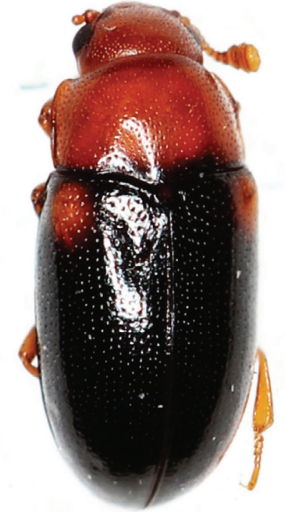

6

Figs. 3-6. Fungivorous beetles associated with Pleurotus ostreatus in the Birch Forest of Onon-Balj National Park. 3. Mycetophagus antennatus, Mycetophagidae. 4. Litargus japonicus, Mycetophagidae. 5. Pseudamblyopus similis, Erotylidae. 6. Dacne bipustulata, Erotylidae. 
Table 1. List of the fungivorous beetles associated with Pleurotus in the birch forest of Onon-Balj National Park in Mongolia.

\begin{tabular}{|c|c|c|c|c|}
\hline \multirow[b]{2}{*}{ Species } & \multicolumn{3}{|c|}{$\begin{array}{l}\text { Khentii, Onon-Balj } \\
\text { National Park, Dadal }\end{array}$} & \multirow{2}{*}{$\begin{array}{l}\text { Cate- } \\
\text { gory }\end{array}$} \\
\hline & $\begin{array}{c}\text { 18.vii. } \\
2012 \\
\text { (pinus) }\end{array}$ & $\begin{array}{c}\text { 20.vii. } \\
2012 \\
\text { (birch) }\end{array}$ & $\begin{array}{c}21 . v i i . \\
2012 \\
\text { (birch) }\end{array}$ & \\
\hline \multicolumn{5}{|l|}{ Order Coleoptera } \\
\hline Lordithon sp. & 0 & & 0 & MX \\
\hline Oxyporus sp. & & & 0 & MB \\
\hline Gyrophaena (Gyrophaena) sp. & 0 & & & MB \\
\hline Gyrophaena (Phaenogyra) sp. & & & 0 & MB \\
\hline Pselaphinae sp. & & & 0 & MX \\
\hline Athetini sp. 1 & 0 & 0 & 0 & MX \\
\hline Athetini sp. 2 & & 0 & & MX \\
\hline Athetini sp. 3 & & 0 & & MX \\
\hline \multicolumn{5}{|l|}{ Family Mycetophagidae } \\
\hline Mycetophagus hillerianus Reitter & & 0 & & MB \\
\hline Mycetophagus antennatus (Reitter) & r) 0 & 0 & 0 & MB \\
\hline Mycetophagus sp.(larva) & & 0 & & MB \\
\hline \multicolumn{5}{|l|}{ Family Erotylidae } \\
\hline Dacne bipustulata (Thunberg) & & 0 & & MB \\
\hline Pseudamblyopus similis (Lewis) & 0 & 0 & 0 & MB \\
\hline Triplax japonica Crotch & 0 & 0 & & MB \\
\hline Erotylidae sp.(larvae) & & 0 & & MB \\
\hline $\begin{array}{l}\text { Family Trogossitidae } \\
\text { Leperina squamulosa (Gebler) }\end{array}$ & & 0 & & MP \\
\hline $\begin{array}{l}\text { Family Nitidulidae } \\
\text { Haptoncus sp. }\end{array}$ & & 0 & 0 & MP \\
\hline Nitidulidae sp. & & 0 & & MP \\
\hline Family Silvanidae & & & & \\
\hline Ahasverus advena (Waltl) & 0 & & 0 & MP \\
\hline Family Tenebrionidae & & & & \\
\hline Adesmia sp. & 0 & & 0 & MP \\
\hline Total & & Families, & 21 specie & \\
\hline
\end{tabular}

*Category (type of association) indicates that the beetle is an obligate/ mycetobiont (MB), a facultative/mycetophile (MP), an accidental/mycetoxene (MX).

gal host, 2) Mycetophiles (MP), which only feed on fungi at some point during their life, but do not require the fungus for development, and 3) Mycetoxenes (MX), which are found occasionally in and around fungi as a simple visitor for shelter.

Host fungi collected for this study were identified using several illustrated mushroom books (Lincoff, 1981; Imazeki and Hongo, 1987; Lee, 1988; Kim et al., 2004) with the assistance of a mushroom taxonomist in the National Academy of Agricultural Science.

\section{Results}

A total of 21 beetle species in seven families were observed to occur on Pleurotus ostreatus Fr. of Onon-
Balj National Park in Mongolia (Table 1). Many taxa were observed as a mycophagy. Fungal host, $P$. ostreatus, has been used by Mongolian beetles as follows: $P$. ostreatus provide approximately 52 percent of the total species with feeding and breeding habitats (mycetobionts), approximately 24 percent with only feeding diets (mycetophiles), and approximately 24 percent with shelters or predation (mycetoxenes).

Staphylinidae was the most common beetle family associated with $P$. ostreatus (eight species, representing five subfamilies. 38\%). The staphylinid beetles listed are of mixed diets, therefore, most of the species are likely to be predaceous and only one species (Oxyporus sp.) is fungivorous. Oxyporus occipitalis typically lay eggs inside a chamber constructed within the gill layer of the host mushroom.

Of the remaining non staphylinoid families, mycetobionts comprised the largest proportion of beetles present, which included Erotylidae (four species, 19\%), and Mycetophagidae (four species, 19\%). And mycetophile comprised Nitidulidae (two species), Trogossitidae (one species), and Tenebrionidae (one species).

Especially, Mycetophagus antennatus (Reitter) (Fig. 3) of family Mycetophagidae (Fig. 4) is the most abundant species associated with Pleurotus in the birch forest of Onon-Balj National Park in Mongolia. Most of larvae and adults of Korean mycetophagids were confirmed to feed and breed in the fruiting bodies of Aphylloporales [e.g. Stereum sanguinolentum (Alb. et Schw.: Fr.); Daedaleopsis tricolor (Bull.: Fr.)] and dried Agaricales [e.g. Armillaria mellea (Vahl) P. Kumm.; Omphalotus japonicus (Kawam.) Kircham. \& O. K. Mill.)], which are lignicolous and longevous. These host fungi are thick enough for this species to feed and breed in fruiting body (Jung and Park, 2013), such as P. ostreatus.

Pseudamblyopus similis (Lewis) in Erotylidae (Figs. 5, 6) is plentiful in the Onon-Balj National Park in Mongolia. Host fungal specificity on Pleurotus is known to some groups, such as the Holarctic Triplax (Erotylidae; Selley et al., 1991). It is suggested that erotylids and mycetophagids are mycophagy because both the larvae and adults were found on the fruiting body of $P$. ostreatus in Mongolia.

Although many beetles that are mycophagous, such as the nitidulid Pallodes, may inhabit on Pleurotus in relatively broad funal host diets (Leschen, 1988), there were two species of family Nitidulidae which maybe considered as a mycetophile because they are commonly inhabit under the bark.

\section{ACKnowledgements}

This work was supported by a grant from the National 
Institute of Biological Resources (NIBR), funded by the Ministry of Environment (MOE) of the Republic of Korea.

\section{REFERENCES}

Benick, L. 1952. Pilzkäfer und Käferpilze, ökologische und statistische Untersuchungen. Acta Zoologica Fennica 70: $1-250$.

Breitenbach, J. and F. Kränzlin. 1986. Fungi of Switzerland, Volume 2 Non gilled fungi (Heterobasidiomycetes, Aphyllophorales, Gastromycetes). Verlag Mykologia, Switzerland, $412 \mathrm{pp}$.

Cline, A.R, and R.A.B. Leschen. 2005. Coleoptera associated with the oyster mushroom, Pleurotus ostreatus Fries, in North America. Southeastern Naturalist 4(3):409-420.

Donisthorpe, H. 1935. The British fungicolous Coleoptera. Entomologist's Monthly Magazine 71:21-31.

Graves, R.C. 1960. Ecological observations on the insects and other inhabitants of woody shelf fungi (Basidiomycetes: Polyporaceae) in the Chicago area. Annals of the Entomological Society of America 53:61-78.

Höfler, K. 1960. Pilzkäfer und Käferpilz. Verhandlungen der k. k. Zoologischen-Botanischen Gesselschaft in Wien 1: 74-83.

Imazeki, R. and T. Hongo. 1987. Colored illustrations of mushrooms of Japan Vol. I. Hiokusha publishing co., Ltd, Japan, 325 pp.

Jung, B.H. and H.C. Park. 2013. Taxonomic review of Mycetophagidae Leach (Coleoptera: Tenebrionoidea) in Korea with their host fungi. Entomological Research 43: 193-200.

Jung, B.H. and J.I. Kim. 2008. Biology of Platydema nigroaeneum Motschulsky (Coleoptera: Tenebrionidae) from Korea: Life History and Fungal Hosts. Journal of Ecology and Field Biology 31(3):249-253.

Jung, B.H. and J.W. Lee. 2011. Fungal hosts of fungivorous tenebrionid beetles (Tenebrionidae) in Korea. The Korean Society of Applied Entomology 50(3):195-201.

Kim Y.S., S.J. Seok, H.Y. Won, K.H. Lee, W.K. Lee and J.S. Park. 2004. The mushrooms of Korea. National institute of agricultural Science and Technology Rural Development Administration. Dongbang media, Seoul, 467 pp. (in Korean)

Klimaszewski, J. and S.B. Peck. 1987. Succession and phylogeny of beetle faunas (Coleoptera) in the fungus Polyporellus squamosus (Huds.: Fr.) Karst (Polyporaceae) in Silesia, Poland. Canadian Journal of Zoology 65:542-550.

Krasutskii, B.V. 2007. Beetles (Coleoptera) Associated with the Polypore Daedaleopsis congragosa (Bolton: Fr.) J.
Schrot (Basidiomycetes, Aphyllophorales) in Forests of the Urals and Transurals. Entomological Review 87(5): 512-523.

Lawrence, J.F. 1973. Host preference in ciid beetles (Col.: Ciidae) inhabiting the fruiting bodies of Basidiomycetes in north America. Bulletin of the Museum of Comparative Zoology 145(3):163-212.

Lawrence, J.F. and R.J. Milner. 1996. Associations between arthropods and fungi. Fungi of Australia 1B:137-202.

Lee, J.Y. 1988. Colored Korean mushrooms (I). Academy, Seoul, 365 pp.

Leschen, R.A.B. 1988. Pallodes austrinus, a new species of Nitidulidae (Nitidulinae) with discussions on Pallodes mycophagy. Journal of the New York Entomological Society 96:452-458.

Leschen, R.A.B. 1990. Tenebrionoid-Basidiomycete relationships with comments on feeding ecology and the evolution of fungal mycophagy (Col. Hymenomycetes). University Kansas Science Bulletin 54:165-177.

Lincoff, G.H. 1981. National Audubon Society, Field Guide to North American Mushrooms. Alfred A. Knopf, Inc., New York. 924 pp.

Nobuchi, A. 1956. Morphological and ecological notes of fungivorous insects. Part I. On the larvae and pupa of Oxyporus germanus Sharp (Coleoptera, Staphylinidae) (with a list of Staphylinid-beetles found on Pleurotus ostreatus (Jacq). Fr. Insect Ecology 5:143-146.

Paviour-Smith, K. 1960. The fruiting bodies of macrofungi as habitats for beetles of the family Ciidae. Oikos 11:4371.

Rehfous, M. 1955. Contribution à l'étude des insectes des champignons. Mitteilungen der Schweizerischen Entomologischen Gesellschaft 28:1-106.

Scheerpeltz, O. and K. Höfler. 1948. Käfer und Pilze. Wien: Verlag für Jugend und Volk. Vienna, Austria. 351 pp.

Skelley, P.E., M.A. Goodrich and R.A.B. Leschen. 1991. Fungal host records for Erotylidae (Coleoptera: Cucujoidea) of America north of Mexico. Entomological News 102:57-72.

Vilgalys, R., A. Smith, B.L. Sun and O.K. Miller. 1993. Intersterility groups in the Pleurotus ostreatus complex from the continental United States and adjacent Canada. Canadian Journal of Botany 71:113-128.

Wheeler, Q.D. 1987. A new species of Agathidium associated with an "epimycetic" slime mold plasmodium on Pleurotus fungi (Coleoptera: Leiodidae-Myxomycetes: Physarales-Basidiomycetes: Tricholomataceae). Coleopterists Bulletin 41:395-403.

Submitted: April 3, 2014, Accepted: August 28, 2014 